\title{
IMAGINATION IN MATHEMATICS
}

\author{
ANDREW ARANA
}

The eminent mathematician Felix Klein wrote, in his intimate history of nineteenth-century mathematics, that "mathematics is not merely a matter of understanding but quite essentially a matter of imagination" (cf. Klein [1979], p. 207). Klein was responding to the turbulent trajectory of imagination's role in mathematics during the nineteenth century, which began with Gaspard Monge teaching new ways of representing three-dimensional figures in the plane to engineers at the École Polytechnique in Paris, and ended with Moritz Pasch fulminating against visualization in geometry. In that light Klein's remark concerns imagination as representation of the visual. But there is another sense of imagination that mathematicians frequently employ: imagination as the ability to think of novel solutions to problems; in other words, ingenuity.

This twofold usage of the term "imagination" was characterized by Voltaire, in his entry on imagination in the Encyclopédie, as distinguishing between what he called the "passive" and "active" faculties of imagination. Both are faculties of every "sensible being" by which one is able "to represent to one's mind sensible things" (cf. Diderot and d'Alembert [I765], p. 560). The passive imagination consists in the ability "to retain a simple impression of objects", while the active imagination consists in the ability "to arrange these received objects, and combine them in a thousand ways". The active imagination is thus the faculty of invention, and is linked with genius, in particular in mathematics: "there is an astonishing imagination in mathematical practice, and Archimedes had at least as much imagination as Homer" (Ibid., p. 56I).

This distinction between imagination as faculty of representation and as faculty of reconstruction, however dubious it may be as cognitive science (on this, cf. Currie and Ravenscroft [2002]), organizes well the two primary ways that mathematicians and philosophers have understood the nature and role of imagination in mathematics. This essay will focus on just the first of these ways, since the second would make for a study of discovery in mathematics, demanding consideration of a rather different set of issues than those called for by the first (cf. Hadamard [I945] for such a study for mathematics, as well as Stokes, "Imagination and Creativity", this volume). It will consider imagination in mathematics in the first sense from a historical point of view, noting the key moments in its conception during the ancient, modern and contemporary eras.

\section{IMAGINATION IN MATHEMATICS IN THE CLASSICAL ERA}

Aristotle [1993] characterized imagination as "that in virtue of which we say that an image occurs to us" (428a I-2), and this seems to have been the basic functional view of imagination in antiquity: a mental faculty capable of receiving and reproducing presentations of the senses. Aristotle also held that imagination can also produce images when no sense perception has taken place, as it does in dreams (428a6), and is thus capable of augmenting thought by unseen images

Date: May I5, 2015.

Thanks to Juliette Kennedy and Sébastien Maronne for comments on drafts of this article. This article is forthcoming in the Routledge Handbook on the Philosophy of Imagination, edited by Amy Kind. 
that are presumably close to what has been seen before. This is an important accommodation since Aristotle seems to hold that all thought, even speculative thought, requires images (432a 3 ; also cf. Modrak, "Aristotle on Phantasia," this volume).

The role of imagination in ancient mathematics was most evident in the reasoning of geometric practice, in which one ordinarily reasoned with diagrams. To illustrate this role, let's briefly consider an example from Euclid. In the first proposition of Elements Book I, Euclid considers the problem of constructing an equilateral triangle (see Figure I). Given a line segment $A B$ to be a side of the triangle, Euclid produces two circles with radius $A B$, centered at $A$ and $B$, respectively. Let $C$ denote one of the points where the two circles intersect, and consider the triangle $\triangle A B C$. Since $A C$ and $B C$ are also radii of their circles, it follows that the three sides are equal, and thus $\triangle A B C$ is equilateral.

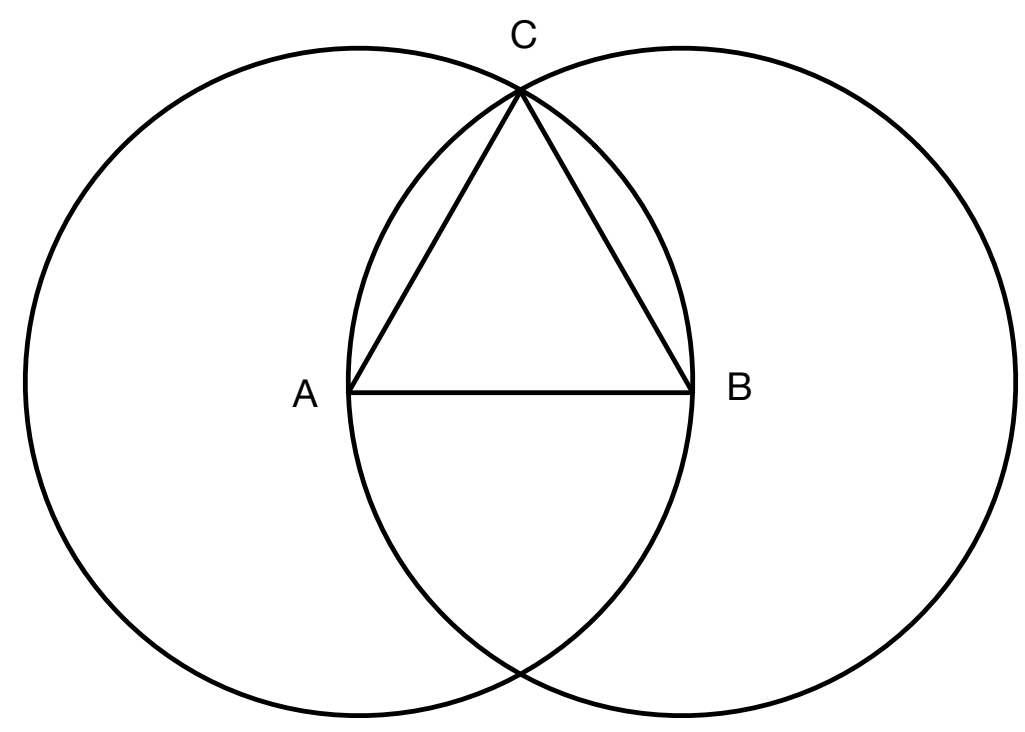

Figure I. Diagram for Elements Proposition I.I

In Greek practice this argument makes essential use of its diagram, as has been cogently argued in Manders [2008]. Such reasoning is characteristic of ancient geometric practice. This highlights the central role of visualization and hence imagination in ancient geometric reasoning, indicating in particular the evidential role of imagination in Greek geometry. This role is invoked by Greek mathematical texts themselves. Reviel Netz (cf. Netz [I999] pp. 52-56, Netz [2009]) has shown that these texts refer to imagination as a cognitive exercise permitting representation of parts of diagrams that are not in the diagram as physical artifact (for instance, as drawn on paper). These texts ask the reasoner to imagine parts of diagrams that would clutter the artifact or would require trying to produce a third dimension in a two-dimensional medium, both representational difficulties that would impede the diagram's usability in reasoning. Thus these texts call on the reasoner to supplement her visual apprehension of the diagram with purely mental manipulations of her representation of the diagram, in order to permit the demanded reasoning.

In contrast, Plato famously judged geometers who described their thinking in terms of productions or constructions, physical or mental, as confused. Texts like those described by Netz are, according to Plato [2004] 527a, "ridiculous accounts" of geometry, given by geometers 
who "speak like practical men, and all their accounts refer to doing things." This is ridiculous, writes Plato, because in fact geometers produce arguments that "are for the sake of knowing what always is, not what comes into being and passes away... for geometry is knowledge of what always is." (527b) Indeed if geometry is to produce knowledge rather than mere opinion it must shun apprehension by construction with its apparent temporality. Thus Plato's conception of mathematical knowledge seems to leave no place for imagination.

While Plato's views were at odds with Greek geometric practice, his influence ensured that these views would continue to be engaged by ancients thinking about mathematical practice (cf. O'Meara [I989]). Of particular importance is the Neoplatonist Proclus, since his commentary on the first book of Euclid's Elements would be well-known in the early modern era by being included in standard translations of the Elements. Writing in late antiquity with access to geometrical and philosophical texts that are now lost, Proclus sought to make sense of the constructive tradition of Greek geometry while remaining true to Plato's insistence upon the eternality of the objects of mathematical knowledge. He reconciled these by distinguishing the role of the understanding from that of the imagination in geometrical thinking: "the understanding contains the ideas but, being unable to see them when they are wrapped up, unfolds and exposes them and presents them to the imagination sitting in the vestibule" (cf. Proclus [I992] p. 44). He explained this "blindness" of the understanding to the ideas of geometry as follows:

We invoke the imagination and the intervals that it furnishes, since the form itself is without motion or genesis, indivisible and free of all underlying matter, though the elements latent in the form are produced distinctly and individually on the screen of imagination. What projects the images is the understanding; the source of what is projected is the form in the understanding; and what they are projected in is this "passive nous" that unfolds in revolution about the partlessness of genuine Nous. (cf. Proclus [I992], p. 45)

Thus the geometrical knower is agent to productions of the imagination, whereby the forms contemplated by the understanding are projected onto the imagination as if onto a screen with the aid of the imagination itself. ${ }^{\mathrm{I}}$

Proclus described these projections as "movement[s] of our thought", whereby the constructions of geometry would take place. As he stressed, "it is in the imagination that the constructions, sectionings, positions, comparisons, additions, and subtractions take place, whereas the contents of our understanding all stand fixed, without any generation or change" (cf. Proclus [i992], p. 64). By means of this epistemological framework Proclus maintained that geometrical knowledge is both produced by construction and arrived at by contemplation of the eternal and unchanging.

According to Proclus, then, knowledge of geometrical propositions like Euclid I. I comes about by the geometer apprehending her constructions by means of imagination, conceptualized like a writing surface on which figures can be produced. Michael Detlefsen has highlighted Proclus' view as providing a foundation for what he calls a "presentist" conception of the rigor of mathematical proofs, on which the rigor of a proof "consist[s] primarily in the keeping of an object continuously before the visual imagination or intuition of the prover during the course

$\overline{{ }^{\mathrm{I}} \text { Both Nikulin }}$ [2008] and Rabouin [2015] provide fuller discussions of the twofold role of the imagination as both passive and as active in Proclus' thought. 
of a proof" (cf. Detlefsen [2005], p. 237). Detlefsen identifies this presentist conception of rigor as operative in classical synthetic geometry, in which constructive, diagrammatic proofs like those of Euclid I.I were the norm. ${ }^{2}$

The presentist conception of rigor would be challenged in the modern era as a competing formalist ideal of proof arose with the development of algebraic methods. Conceptions of the role of imagination in mathematical thinking shifted alongside the rise of algebraic methods. The next section traces this cluster of changes in modern mathematics.

\section{IMAGINATION IN MATHEMATICS IN THE MODERN ERA}

The Middle Ages saw the locus of geometric investigation move to the Arab world, where geometers continued in the classical tradition with initial excursions into algebra (cf. Rommevaux [2009]). In the sixteenth century the Latin translations of Pappus, Euclid, Proclus and other classical mathematical texts by Francesco Barozzi and Federico Commandino inaugurated a resurgence of interest in geometry in the Renaissance West. The Jesuit Christoph Clavius reformed the mathematics education of his order's schools (including La Flèche, where Descartes would be educated), publishing his own edition of the Elements as well as a text on algebra that brought together Italian and German advances in the theory of equations birthed in the Arab world (cf. Sasaki [2003], Chapter 2).

In addition to the expected Aristotelianism, Clavius' writings evinced Neoplatonist leanings reflecting his interest in Proclus, and these leanings would influence in particular reflections on the role of imagination in mathematics in the seventeenth century. For instance, the Neoplatonist Giuseppe Biancani published in I6I 5 a commentary on the parts of Aristotle's work that address mathematics, and included a supplement on the nature of mathematics. Biancani differentiated reasoning and imagination following Plato's discussions of each in Book VII of the Republic, arguing that reasoning rather than imagination is the source of mathematical knowledge, since "anyone who considers geometrical demonstrations will clearly see that they work not by flimsy imagination, but by very complicated reasonings, for there are many in which fifty to sixty inferences are connected to one another... but imagination lacks any inferences" (cf. Mancosu [1996], pp. 199-200).

Views toward imagination in mathematics shifted in a genuinely new way with René Descartes. Until the I630s, Descartes' mathematical accomplishments were an extension of the constructive tradition of classical geometry, furthering a program that had been started by François Viète (cf. Viète [1983]). Classical geometers concerned themselves with the construction of figures, but they characteristically took the methods legitimate for such construction to be restricted in certain ways (e.g. to ruler and compass). The ancient consensus seems to have been that the knowledge of figures produced by construction, and of those constructions themselves, was warranted only to the extent that those constructions consisted of motions that were traceable with sufficient exactness. Certain constructions, like that of the spiral-sweep a ray fixed at a central point at a uniform speed while also uniformly moving a point along that ray, and trace a curve by that moving point-were judged to be "mechanical" and hence inexact by e.g. Pappus, but the ancients never satisfactorily articulated a criterion of which constructions were adequately exact.

$\left.\overline{{ }^{2} \text { Rabouin }[20 \mathrm{I}} 5\right]$ shows how Proclus' view of imagination accommodates proofs by reductio in classical geometry as well. 
Pursuing this unresolved ancient issue, in La Géométrie Descartes posited that the legitimate curves were those that can be "imagined to be traced by a continuous motion or by several successive motions where the latter ones are entirely regulated by those which precede" (AT VI, p. 390). These constructions were to be carried out using instruments, and since his early twenties Descartes had been developing new compasses that satisfied this "single motion" criterion (cf. Bos [200I], pp. 237-25I). By noting that these constructions could be "imagined" rather than carried out publicly, Descartes was endorsing a view of imagination's role in geometrical knowledge that he had inherited from Proclus. A more explicit endorsement of this view was given by Descartes' contemporary Johannes Molther, who wrote as follows:

But if someone would judge that geometry at its most pure should be practiced just by action of the mind and based only on its postulates, then even he would idealize, by mathematical abstraction, the ideas of a material ruler, or a compass, and he would grasp these ideas in his mind so that rulers and compasses would do their work by an interior sense in the imagination. And thus it would be easy to imagine thinkingly the process of which we have shown how it is performed in reality. (cf. Bos [200I], p. 200)

As a consequence of this view, the legitimacy of a method of construction was determinable by whether that method could be carried out in the imagination with adequate clarity and distinctness. Thus Descartes held that constructions meeting his "single motion" criterion of geometric legitimacy were as legitimate in geometry as the classical constructions using just ruler and compasses, because all such constructions required the imagination to control only one motion at a time. By contrast, the usual construction of a spiral demanded the control of two independent motions. ${ }^{3}$ While in La Géométrie Descartes offered no explanation of why the single motion criterion should determine which constructions are legitimate in geometry, he offered considerations that permit such an explanation in La Dioptrique, published alongside La Géométrie with the Discours de la Méthode in I637. He wrote there that "it is impossible to see more than one sole object at a time distinctly" (AT VI, p. I63), so that a construction demanding visual attention to more than one object, as in the case of the spiral, could not be carried out with adequate distinctness to generate knowledge of the resulting curve. ${ }^{4}$ Thus Descartes' justification for his extension of classical geometry to new methods of construction rested on a psychological commitment concerning the limits of visual attention, and by virtue of the close connection between vision and imagination for Descartes, of the limits of imagination (cf. Sepper, "Imagination in Descartes," this volume).

As Rabouin [2010] has argued, Descartes did not develop his method of applying algebra to geometry until the early I630s. This work, published in La Géométrie in I637, brought about a dramatic shift in views toward imagination in mathematics. Though not the first work suggesting that algebra could be applied to geometry (cf. Panza [2007] for details on the Arabic tradition preceding the Cartesian turn), it presented a systematic program for such application. This application of algebra to geometry permitted the solution of geometrical problems by

\footnotetext{
${ }^{3}$ Whether there exists a construction meeting the single motion criterion that can construct the spiral was a metatheoretic question of the kind falling beyond the scope of Descartes' conceptual framework; cf. Crippa [20I4] for more on this question.

${ }^{4}$ On this also see Rule 9 of the Regulae ad directionem ingenii, though as a text unfinished and unpublished during Descartes' life, one should be careful in putting hermeneutical weight on it.
} 
means of calculations for which one need have no visual representation of the relevant quantities in order to carry out.

To illustrate this new method of geometric problem solving, let us consider a particularly clear example taken from Bernard Lamy's textbook Lamy [I692] (pp. 3 I 5-3 I7), an important text in the diffusion of Descartes' methods in the seventeenth century. For $\triangle B A C$ an isosceles triangle, Lamy raises the problem of cutting the sides $A B$ and $A C$ by a line $D E$ parallel to the base $B C$ such that $D B=D E$. Lamy presents two solutions to this problem, to show how a purely geometrical ("synthetic") solution differs from a solution that applies algebra.

In the first solution (see the left diagram of Figure 2), we begin by bisecting $\angle A B C$. Let $E$ denote the point where the bisecting line cuts $A C$. Construct a line parallel to $B C$ through $E$, and call this segment $D E$. Then $\angle C B E$ and $\angle D E B$ are alternating angles and hence congruent. Since $\angle C B E$ and $\angle D B E$ are congruent by bisection, it follows that $\angle D B E$ and $\angle D E B$ are congruent. Then $\triangle D B E$ is isosceles, and so $D B=D E$, as we wanted to produce.

In the second solution (see the right diagram of Figure 2), let $a$ denote the given quantities $A B=A C$, and let $d$ denote $B C$. Let $D$ denote a point between $A$ and $B$, and let $x$ be $A D$, so that $D B$ has length $a-x$. We want to find $x$ such that $D E$ also has length $a-x$. Since $\triangle A D E$ and $\triangle A B C$ are similar triangles, we have that

$$
\frac{a}{d}=\frac{x}{a-x}
$$

Then

which implies that

$$
x d=a(a-x)=a^{2}-a x
$$

$$
a^{2}=x d+a x=x(d+a)
$$

and thus

$$
x=\frac{a^{2}}{d+a}
$$

the quantity we wanted to find.

As noted earlier, the first solution relies on purely geometrical reasoning, while the second uses algebraic reasoning as well. Note that the algebraic reasoning in the second proof is not interpreted geometrically; after establishing the ratio (I) geometrically, the solution proceeds algebraically, with a series of computations that are not interpreted geometrically, and need not be in order for the solution to succeed.

Descartes lauded his method for providing proofs with the latter characteristic. As he put it in the Discours, ancient geometry was "always so attached to the consideration of figures that it cannot exercise the understanding without greatly tiring the the imagination" (AT VI, pp. I7-I 8). The algebraic steps of his method permitted the solver to avoid imagining the figures being considered, and thus afforded a significant economy of thought. As Descartes knew, the solutions of some geometric problems involved quite complex diagrams, with dozens of lines and circles (not to mention the chiliagon). Keeping track of the relevant pieces while reasoning about such figures was rather demanding on the imagination of problem solvers.

Descartes' view takes a stand on what came to be a central dispute in the eighteenth and nineteenth century: ought one of these types of reasoning, geometric or algebraic, have priority over the other in geometric problem solving? Not only did Descartes proclaim the value of algebraic methods in reducing demands on the imagination, he also declared it a better method 

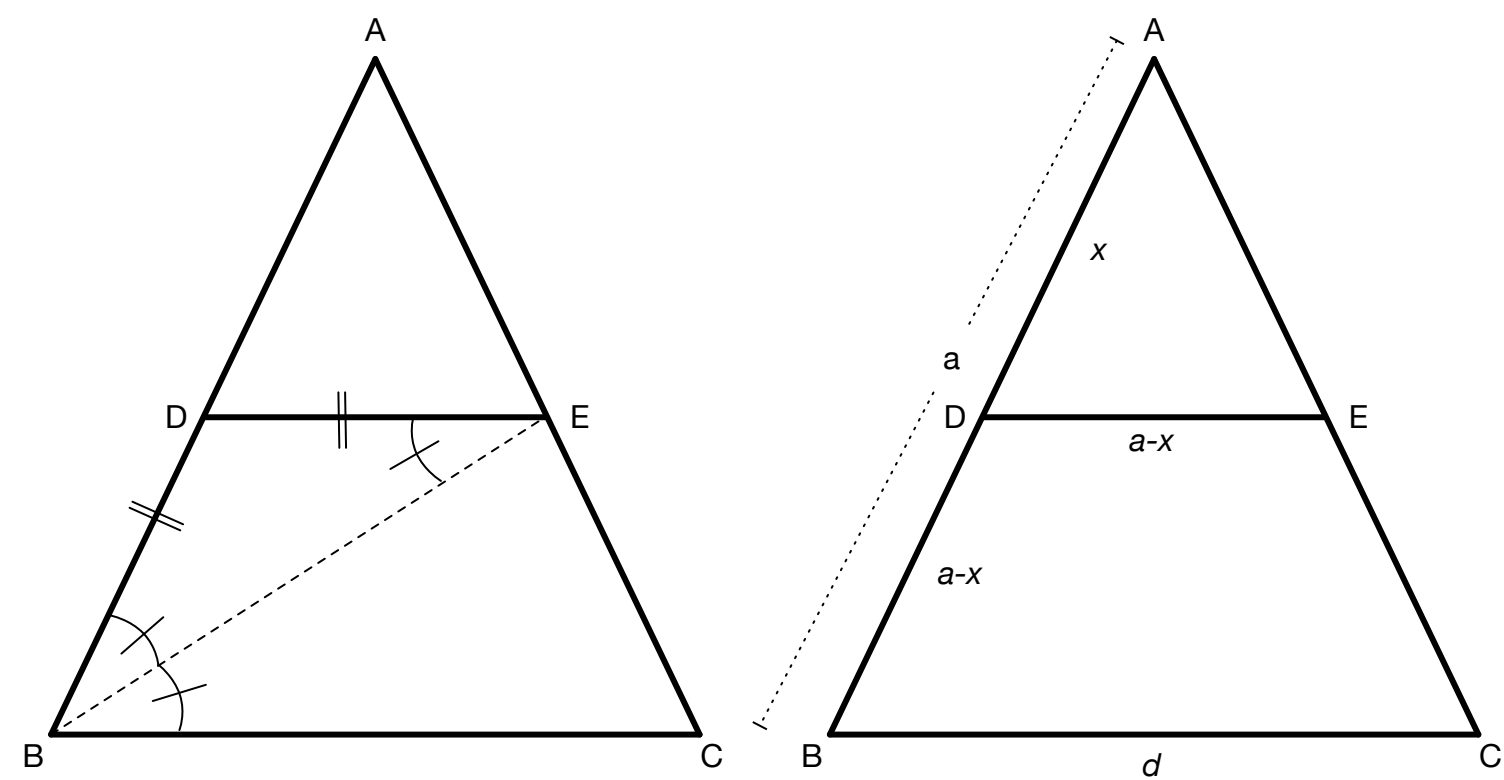

Figure 2. Diagrams for Lamy's example

for the discovery of new solutions. In taking this stand, however, Descartes offered a challenge to the presentist ideal of rigor offered by Proclus. The presentist ideal maintains that the rigor of a proof consists in a follower of that proof keeping the objects of the proof in view, employing not only visual perception but also imagination and memory. In addition to rigor, an advocate of geometric reasoning over algebraic reasoning may hold that the employment of imagination provides for mathematical understanding by enabling apprehension of visualizable content itself. Descartes' view suggests a counter-ideal to these, in which the role of imagination in geometric knowledge recedes as algebraic methods provide for more efficient and indeed more general knowledge, since algebra is not limited to quantities that are readily visualizable.

This dialectic came to blossom during the eighteenth and nineteenth centuries, but it began picking up steam already in the late seventeenth century with the further development of algebraic analysis. For instance Gottfried Wilhelm Leibniz, in letters to Christiaan Huygens in the I690s, promoted his new infinitesimal methods in terms of the relief it provides to the imagination:

For what I love the most about this calculus is that it gives us the same advantage over the ancients in Archimedes' geometry that Viète and Descartes gave us over the geometry of Euclid or Apollonius, by relieving us of the use of the imagination. (letter dated 8 January I692; cf. Huygens [I888-I950], p. 227)

In another letter to Huygens he specified that the imagination was to be avoided because it "often works as by chance" (letter dated 2I September I69I; cf. Huygens [I 888-I950], Volume $\mathrm{X}$, p. I 57). Leibniz thus judged the imagination both overly laborious and unmethodical in problem solving, compared with algebraic analysis.

This burgeoning philosophical dispute was shaped as well by purely mathematical concerns, in particular to limitations of algebraic analysis, to which practitioners became attuned as knowledge of algebraic methods spread. Descartes himself was aware of these limitations, 
having recounted to Princess Elisabeth a problematic algebraic solution to Apollonius' problem of the three circles (given three circles in a plane, construct a circle touching all three). In November I643 Descartes suggested to Elisabeth that she practice her algebraic skills by finding an algebraic analysis for this problem (in the case when the given circles have a triangular arrangement), having pursued his own algebraic analysis (AT IV, pp. 46-47). His suggestion was presumably ironic, since he explained to her how to find an equation whose solution could be used to solve the problem, but did not actually present this equation, presumably because he knew (but did not say) that the equation has eighty-seven terms, each a product of six factors (cf. Henk Bos' essay in Verbeek et al. [2003] for details). Descartes was content with discovering how to solve a problem, without carrying out the details. ${ }^{5}$ That luxury, afforded to him in virtue of being a theoretician, was not available to those who sought to employ algebraic analysis in order to solve problems in full detail (for instance, in mathematical physics or other applied work). Thus the relief to the imagination allegedly offered by algebraic analysis brought with it other intellectual costs, and the reckoning between these costs would occupy considerable attention in the future.

Descartes' views on imagination influenced many in the ensuring years, but special attention should be given to their transformation in the works of Nicolas Malebranche. This is because Malebranche's extensive criticisms of imagination were received widely by mathematicians, as a result of his followers including several writers of mathematical textbooks that would play a key role in the diffusion of Cartesian algebraic analysis. Like Descartes, Malebranche emphasized the importance of visual attention for geometrical knowledge, noting that geometers who use algebraic analysis recognize that "their minds cannot be applied to several figures at the same time" and thus apply algebra so that they can "perceive all in one glance what they would not be able to see otherwise" (cf. Malebranche [I674] 3.I.3, p. 332).

While pursuit of geometry can improve the attentiveness of the mind by giving it occasion to exercise control over the imagination, its being "evident and very agreeable" was also a source of error for the geometer (cf. Malebranche [I675] 6.4, p. 290). For Malebranche held that the love of pleasure prevents us from discovering the truth, since pleasure is concerned with the sensible, which points us away from God, in whom alone truth can be found. Malebranche argued that "it is necessary that the senses and the passions are silent, if one wants to hear the word of truth, distance from the world and contempt for all sensible things being necessary as much for the perfection of the mind as for the conversion of the heart" (cf. Malebranche [I675] 4.II , p. 85). This is cause for the geometer to favor algebraic analysis over the synthetic reasoning of the ancients, Malebranche continues, not only because of its fruitfulness, certitude, and its ability to direct the mind "infallibly to its goal" but more importantly because it has "nothing dazzling nor attractive for men for the sole reason that it has nothing sensible" (Ibid., p. 87). The pursuit of geometrical knowledge by algebraic means thus protects the geometer from the temptations of the imagination, which lead toward pleasure and thus sin. ${ }^{6}$

Around the turn of the eighteenth century three mathematicians deeply influenced by Malebranche, Jean Prestet, Bernard Lamy, and Charles-René Reynaud, published mathematical

${ }_{5}$ Indeed, he seemed to think the knowledge one has when one knows how to solve a problem is much more valuable than the further knowledge gained by actually carrying out the discovered procedure in detail; cf. Maronne [2010].

${ }^{6}$ Malebranche's criticisms of the imagination echo those of Pascal; cf. Pascal [2015]. A fuller treatment of Malebranche's philosophy of mathematics can be found in Robinet [I96I]. 
textbooks that, as mentioned before, were crucial in the diffusion of Cartesian algebraic analysis, bridging the generations between Descartes and Lagrange. ${ }^{7}$ Prestet [I689] included a brief discussion of geometry in the style of Euclid (without giving figures), turning then to an extensive discussion of the elements of algebra. Prestet justified this organizational imbalance between classical geometry and algebra in Malebranchian terms: "Because as all sciences ought to aim at enlightening the mind, one ought not highly esteem the use of these expressions by lines that speak only to the eyes and to the imagination" (cf. Prestet [I689], p. xv). One ought to favor algebraic over classical geometric methods, he continued, because "the study of mathematics is very proper for learning to dispel the illusions of the senses, to correct the derangement of the imagination, and to moderate the proud impetuousness of our passions" (cf. Ibid., pp. xviii-xix). ${ }^{8}$

Lamy [I692], from which the example of algebraic analysis given above was drawn, includes treatments of geometry by both the classical and analytical methods. He emphasized that the latter approach was general, while classical solutions were by contrast "particular and proper to the sole problem" to which they were directed (p. 317). He seems to have meant that the analytic method, designating unknown quantities by variables, using the configurations occurring in the problem to set up equations, and then solving these equations by analytic means, did not demand attention to the particular geometric configurations represented by those equations or calculations. Its reasoning, once the equations were set up, could proceed without further reference to the figure. A classical solution on the other hand must employ geometric propositions involving for instance similarity and congruence in its reasoning, and these reasonings demand steady attention to the figure. Analytic reasoning thus reduces the need for visual attention by means of the imagination. He lauded this feature of such proofs, expressing again in Malebranchian terms that reducing the use of imagination had spiritual benefits:

We can only see by the imagination that which is bodily; those therefore that make use only of their imagination cannot perceive spiritual things, they do not even believe there to be any [spiritual things], because they find no images in their imagination; just as in seeking bodies with the hands, if we find nothing that resists, we believe that there is nothing. (cf. Lamy [I692], p. ii; also cf. Gregory, "Imagination and Mental Imagery," this volume)

Reyneau [1708] was the last of these textbooks to appear. Malebranche praised it in later editions of De la recherche de la vérité, and it was one of the key texts in d'Alembert's mathematical education. Reyneau like Lamy stressed the Cartesian method of applying algebraic analysis to geometry, though most of the text's pages are devoted to the details of solving algebraic equations. Like Prestet and Lamy, Reyneau described the value of his methods in Malebranchian terms. Human minds are limited in that they cannot see in a single view many objects at the same time. Thus classical geometric reasoning is overly demanding on the imagination, and for its relief the geometer turns to algebraic analysis. He described this relief in the following terms: These new methods, reducing geometry to a simple and easy calculus, released that which had been encumbered by figures, that is to say, all that had tired the imagination, and had filled the capacity of the mind. They left it the freedom to

7 Both Lamy [1692] and Reyneau [I708] were lauded by Rousseau in Les confessions, Book VI.

${ }^{8}$ Cf. Schubring [2005], pp. 52-6I, 69-73, for a discussion of Prestet's orientation and relation to Malebranche. 
penetrate its subject, and to discover with evidence all that had been closed. (cf. Reyneau [I708], p. iii)

These texts of Prestet, Lamy and Reyneau marked a turning point in conceptions of the role of imagination in mathematics. By being published in textbooks lodged in mainstream eighteenth century mathematics, their views had reach among practitioners that philosophical texts could not. They helped normalize a narrative of the value of algebraic analysis and its role for displacing reliance on imagination in geometry that would persist into the nineteenth century. Jean d'Alembert for instance would write of algebra in his Encyclopédie entry on it that "it relieves the memory and imagination in diminishing many of the efforts that it would have been obliged to make for retaining the different things necessary for the discovery of the truth for which it worked, and that one wanted to keep in mind" (cf. Diderot and d'Alembert [175 I], p. 259). He expanded on this in his entry on the application of algebra to geometry:

[W] hen I designate all the lines by algebraic characters, I will be able to carry out many operations on these characters, while thinking of neither the lines nor the figure, and this is an advantage it has. It relieves the mind, because when using analysis the mind does not have to use all its forces to solve certain problems; the use of analysis saves these forces as much as possible. (cf. Diderot and d'Alembert [I75I], p. 55I)

Thus algebraic analysis in geometry is valuable according to d'Alembert because of its "opacity": it permits geometric problem solution without imagination of the figure being investigated.

As the eighteenth century closed, Condorcet published a retrospective on the century's accomplishments in the guise of an elegy for the recently departed Leonhard Euler. In contrast to the views just recounted, he lamented the laboriousness of algebraic work, noting that "the rigor with which it separates from this idea [of magnitude] everything which, by occupying the imagination, could give some rest to the intellect" rendered it "too foreign to our nature" as agents for whom imagination plays a central role in cognition, and too "distant" from ordinary thought, for humans to use these methods with ease (cf. Condorcet [I786], p. 42). The application of algebra to geometry forces geometers to forget the object they seek, and "the goal where one wants to arrive, the point from where one left, disappear equally in the eyes of the geometer" (Ibid.) Condorcet's view offered a renewed defense of imagination in mathematics, against the other eighteenth century views surveyed here. It thus presaged developments in the nineteenth century to which we now turn.

\section{IMAgination in Mathematics SinCE THE NiNeTEenth CENTURY}

The debate between advocates of algebraic and classical "synthetic" methods in geometry continued with an attempt at reconciliation by the school of Gaspard Monge. Monge's teaching in descriptive geometry at the École polytechnique, in which he taught new ways to represent three-dimensional figures in two dimensions, emphasized an intimate correspondence between analytic computations and classical-style constructions, so that "there is no construction of descriptive geometry that cannot be translated into analysis... [and] each analytic operation can be regarded as the writing of a geometrical presentation [spectacle]" (cf. Monge [i 795], p. I6, reprinted in Dhombres [I989]; cf. Chemla [I998], p. I66 also). As Belhoste [I998] stresses, Monge's teaching would carry a considerable influence in the nineteenth century. Michel Chasles, a member of Monge's school, characterized the "useful influence of descriptive 
geometry" on geometry more generally by noting that it frees geometrical reasoning "from this complication of figures whose usage distracts the attention that one fundamentally owes to the ideas, and hinders imagination and language" (cf. Chasles [i 837], p. I90). The improved focus provided to the imagination described here can be illustrated by turning to projective geometry, whose development blossomed during the nineteenth century.

The idea of projective geometry is to study configurations of points and lines that are unchanged when we "project" those configurations. By "projecting" one can think for instance of projecting a globe onto a plane to make a map, representing a shift in perspective of an observer. Such projections were the means by which Renaissance artists draw realistic perspectives. A key was noting that to get such perspectives to look right, parallel lines had to meet at the horizon. Thus projective geometry includes a point at infinity, where parallel lines meet. Projective geometry is thus the study of configurations of points and lines, including a point at infinity, that are invariant under projective transformations like the globe one just described.

Though geometers before the nineteenth century had pursued projective geometry, its development took flight with the work of Jean-Victor Poncelet, a member of the school of Monge. Poncelet noted that in "ordinary geometry", one "never loses sight" of the figure and "never draws consequences that cannot be painted in the imagination or in sight by sensible objects" (cf. Poncelet [1 822], p. xxi). The projective geometer too attends to figures, but employs a rather different notion of figure, one which may not be accessible to imagination, at least not as traditionally conceived. Jemma Lorenat has illuminated this new notion of figure arising in nineteenth century geometry in Lorenat [2015]. Lorenat draws on work of Dominique Tournès that identifies a type of diagram called a "virtual diagram", a diagram "that one must have in mind, but that is no longer physically drawn on the paper, or at least which is left to the reader to draw" (cf. Tournès [2OI2], p. 272). Instead, these diagrams are described in words, either text or speech. The typical failure of such descriptions to specify fully the intended figure avails the geometer of generality: her reasoning need not refer only to a single figure, but to any figure meeting the given specifications. This sort of generality had been an important part of earlier cases for the superiority of algebraic reasoning, since algebraic variables range over classes of objects.

Additionally, virtual figures permit the geometer to work with figures containing what were called "imaginary" points, like the points at infinity described earlier. Michel Chasles characterized an imaginary point as a "being of reason without existence, but to which one can however suppose some properties which one uses momentarily like an auxiliary, and to which one applies the same reasonings as to a real and palpable object" (cf. Chasles [I837], p. 207). While the ontology of such points remained unclear, and while such points are not visualizable in any ordinary sense, Lorenat observes that Poncelet manipulated figures with such points by projective transformations, since the relations these points have with non-imaginary points are projectively invariant. Thus imaginary points could be visualized and imagined indirectly, by attending to their relations with non-imaginary points (cf. Lorenat [2015], p. I 88). This practice thus involved a new, indirect mode of visualization and imagination.

The nineteenth century also saw the rise of non-Euclidean geometries, which put further pressure on the classical conception of geometry and thus on the role of imagination in geometric thought. Until the nineteenth century Euclidean geometry was widely believed to be the geometry of human perceptual space (cf. Andersen [2007]). Euclidean geometry includes a parallel axiom, which entails with the other Euclidean axioms that for any line and point 
not on that line, there exists a unique line parallel to the given line through the given point. Non-Euclidean geometries, by contrast, include a negation of this axiom. By the end of the nineteenth century geometers were largely convinced that both Euclidean and non-Euclidean geometries were legitimate mathematical theories, since they were equiconsistent (cf. Gray [2007], Chapter 20). This left open the question of which of these geometries, if any, was the geometry of perceptual space.

Immanuel Kant's critical philosophy seemed to be committed to answering this question in favor of Euclidean geometry, and this problematized the impact of Kant's critical philosophy on mathematics. Kant's mathematical epistemology gave a central place to constructive knowledge, with the practice of classical synthetic geometry serving as a paradigm for it. Kant gave a role to imagination in the syntheses that, as he saw it, ground such knowledge; recent work, for example Domski [2010] and Friedman [2000], help clarify some of the obscurities in his approach. But Kant's evident commitment to Euclidean geometry over its alternative blunted its applicability to mathematics as it actually stood by the end of the nineteenth century. Several philosophers attempted to reconcile Kant's views with the legitimacy of non-Euclidean geometries (cf. Gray [2008], in particular sections I.2.I, 6.2.3, 6.2.4); most notably Hermann von Helmholtz argued that non-Euclidean geometry is in fact imaginable, making his case on Kantian terms (cf. Helmholtz [I884]).

Kant's views were also challenged by the acceptance of imaginary points in geometry discussed above, since it is hard to see how non-visualizable points can be the object of synthetic judgment. Jeremy Heis has argued that Ernst Cassirer, a neo-Kantian philosopher eager to reconcile Kant's critical philosophy with contemporary geometry, judged imaginaries legitimate in geometry because of their role in "unifying and explaining facts about the so-called 'real' points" (cf. Heis [20I I], p. 783). They thus play the role of "ideals" in Kantian terms, in that they help regulate cognition despite not being able to be given in experience.

David Hilbert, whose axiomatization of geometry Hilbert [1899] permitted a newly clear conception of the metamathematics of non-Euclidean geometry, was also strongly influenced by Kant's views. Hilbert acknowledged the value of Pasch's reconceptualization of geometry, in which deduction is required to be "independent of figures" in order to be rigorous (cf. Pasch [1882], p. 43, and Schlimm [2010]). Such reasoning could contain no tacit appeals to unacknowledged visual content, which might jeopardize its validity by importing an unacknowledged assumption. But this metamathematical goal of ensuring rigor did not override Hilbert's interest in the intuitive or imaginative. In his work on the foundations of arithmetic and analysis (most notably Hilbert [1926]) Hilbert divided mathematics into a "real" part that is finitary and contentual, and a non-contentual "ideal" part (again echoing Kant) that concerns, for instance, imaginary numbers and infinitary propositions in analysis and set theory. The objects of real mathematics were said to be finite strings of symbols, and hence visualizable. He then outlined a project to prove the consistency of ideal mathematics by real means, a project whose feasibility is widely believed to have been undermined by the incompleteness theorems of Kurt Gödel. Hilbert's interest in imagination also carried over into his work on geometry, notably in Hilbert and Cohn-Vossen [I932] which sought to give

a presentation of geometry, as it stands today, in its visual, intuitive aspects. With the aid of visual imagination we can illuminate the manifold facts and problems of geometry, and beyond this, it is possible in many cases to depict the geometric 
outline of the methods of investigation and proof, without necessarily entering into the details connected with the strict definitions of concepts and with the actual calculations. (cf. Hilbert and Cohn-Vossen [1952], p. iii).

Hilbert thus sought to provide for geometrical knowledge not by requiring one to follow each step of an analytic treatment or a deductive proof, but rather by enabling "intuitive understanding" by means of the imagination.

Recently philosophers of mathematics have begun considering the role of imagination in mathematics from a cognitive point of view (cf. Mancosu [2005] for an overview of this work). Marcus Giaquinto has given a detailed exploration of visual thinking in mathematics in Giaquinto [2007], attending not only to diagrammatic reasoning in geometry but also to visual arithmetic reasoning. For arithmetic Giaquinto considers whether humans have an innate "number sense" for judging which of two numbers is larger in the light of contemporary work in cognitive psychology. For geometry he draws on recent psychological work on visual perception to describe what he calls "visual category specifications" for visual objects like squares; these are sets of features whose detection by our visual apparatus suffices for perceiving a figure as an object of that category. These specifications determine what he calls "perceptual concepts" of particular shapes. Possession of such perceptual concepts amounts to the disposition to judge an object of perception to have the shape specified by such a concept when that perception seems to be reliable. A perceptual concept is a geometric concept when its possession conditions also include the disposition to judge an object of perception to have the shape specified by the concept in a perfect way. He finally explains that these belief-forming dispositions can be triggered by visual experiences, and that when these dispositions are reliable, the resulting beliefs are knowledge.

\section{Conclusions}

This article has surveyed the nature and role of imagination in mathematics from antiquity through today. Particular attention has been given to the seventeenth and eighteenth centuries because they witnessed the transformation of ancient views on imagination into guises that would be approached in novel ways thereafter. Despite the challenge posed to imagination by the rise of algebraic methods in the seventeenth century, there remains today an important role for it.

\section{REFERENCES}

Kirsti Andersen. The Geometry of an Art: The History of the Mathematical Theory of Perspective from Alberti to Monge. Springer, New York, 2007.

Aristotle. De Anima Books II and III (with passages from Book I). Clarendon Press, Oxford, I993. Translated with introduction and notes by D.W. Hamlyn.

Bruno Belhoste. De l'École Polytechnique à Saratoff, les premiers travaux géométriques de Poncelet. Bulletin de la Société des Amis de la Bibliothèque de l'École Polytechnique, I9:9-29, June I998.

Henk J. M. Bos. Redefining Geometrical Exactness. Springer, New York, 200I.

Michel Chasles. Aperçu Historique sur l'Origine et le Développement des Méthodes en Géométrie. M. Hayez, Bruxelles, I 837. 
Karine Chemla. Lazare Carnot et la généralité en géométrie. variations sur le théorème dit de Menelaus. Revue d'histoire des máthematiques, 4:I68-I90, I998.

Nicolas de Condorcet. Eloge de Euler. Histoire de l'Académie royale des sciences pour l'année I783, pages 37-68, I786. Reprinted in Condorcet [I 804].

Nicolas de Condorcet. Oeuvres complètes de Condorcet, volume III. Vieweg, Brunswick, I804. Davide Crippa. Impossibility Results: From Geometry To Analysis. PhD thesis, Université Paris 7 Denis Diderot, 20I4.

Gregory Currie and Ian Ravenscroft. Recreative Minds. Oxford University Press, Oxford, 2002. René Descartes. Oeuvres, volume IV. Léopold Cerf, Paris, I90 I. Edited by Charles Adam and Paul Tannery.

René Descartes. Oeuvres, volume VI. Léopold Cerf, Paris, I902. Edited by Charles Adam and Paul Tannery.

Michael Detlefsen. Formalism. In Stewart Shapiro, editor, Handbook of the Philosophy of Mathematics and Logic, pages 236-3 I7. Oxford University Press, New York, 2005.

Jean Dhombres, editor. L'École Normale de l'An III, Leçons de Mathématiques, Laplace-LagrangeMonge. Dunod, Paris, I989.

Denis Diderot and Jean Le Rond d'Alembert. Encyclopédie ou Dictionnaire raisonné des sciences, des arts et des métiers, volume I. Briasson, David, Le Breton, and Durand, Paris, I75I.

Denis Diderot and Jean Le Rond d'Alembert. Encyclopédie ou Dictionnaire raisonné des sciences, des arts et des métiers, volume 8. Briasson, David, Le Breton, and Durand, Paris, I765.

Mary Domski. Kant on the imagination and geometrical certainty. Perspectives on Science, I 8(4): 409-43I, 2010.

Euclid. The thirteen books of Euclid's Elements translated from the text of Heiberg. Vol. I: Introduction and Books I, II. Dover Publications, New York, I956. Trans. with introduction and commentary by T. L. Heath, 2nd ed.

Michael Friedman. Geometry, construction and intuition in Kant and his successors. In Gila Sher and Richard Tieszen, editors, Between Logic and Intuition: Essays in Honor of Charles Parsons, pages I 86-2 I 8. Cambridge University Press, Cambridge, 2000.

Marcus Giaquinto. Visual thinking in mathematics. Oxford University Press, Oxford, 2007.

Jeremy Gray. Worlds Out of Nothing. Springer, London, 2007.

Jeremy J. Gray. Plato's Ghost. Princeton University Press, Princeton, 2008.

Jacques Hadamard. The Psychology of Invention in the Mathematical Field. Princeton University Press, Princeton, I945.

Jeremy Heis. Ernst Cassirer's neo-Kantian philosophy of geometry. British Journal for the History of Philosophy, I9(4):759-794, $20 \mathrm{I}$ I.

Hermann von Helmholtz. Ueber den Ursprung und die Bedeutung der geometrischen Axiome. In Vorträge und Reden, volume 2, pages I-3 I. Vieweg, Braunschweig, I 884.

David Hilbert. Grundlagen der Geometrie. B.G. Teubner, Leipzig, I 899.

David Hilbert. Über das Unendliche. Mathematische Annalen, 95(I):I6I-I90, I926.

David Hilbert and Stephan Cohn-Vossen. Anschauliche Geometrie. Springer, Berlin, I932.

David Hilbert and Stephan Cohn-Vossen. Geometry and the Imagination. Chelsea Publishing Company, New York, I952. Translation of Hilbert and Cohn-Vossen [I932] by P. Neményi.

Christiaan Huygens. Oeuvres complètes de Christiaan Huygens. Martinus Nijhoff, The Hague, I 888-I950. 22 volumes. 
Felix Klein. Development of Mathematics in the Igth Century. Math Sci Press, Brookline, MA, I979. Translated by M. Ackerman.

Bernard Lamy. Nouveaux élemens de geometrie ou de la mesure du corps. André Pralard, Paris, I692.

Jemma Lorenat. Figures real, imagined, and missing in Poncelet, Plücker, and Gergonne. Historia Mathematica, $42(2): 155-192$, 2015.

Nicolas Malebranche. De la recherche de la vérité, volume I. André Pralard, Paris, I674.

Nicolas Malebranche. De la recherche de la vérité, volume II. André Pralard, Paris, I675.

Paolo Mancosu. Philosophy of Mathematics and Mathematical Practice in the Seventeenth Century. Oxford University Press, New York, 1996.

Paolo Mancosu. Visualization in logic and mathematics. In Paolo Mancosu, Klaus Frovin Jørgensen, and Stig Andur Pedersen, editors, Visualization, Explanation and Reasoning Styles in Mathematics, pages I3-28. Springer, Dordrecht, 2005.

Kenneth Manders. The Euclidean diagram. In Paolo Mancosu, editor, The Philosophy of Mathematical Practice, pages 80-I 33. Oxford University Press, Oxford, 2008.

Sébastien Maronne. Pascal versus Descartes on geometrical problem solving and the Sluse-Pascal correspondence. Early Science and Medicine, I 5:537-565, 2010.

Gaspard Monge. Leçons à l'École Normale de l'An III. In Dhombres [I989]. I795.

Reviel Netz. The Shaping of Deduction in Greek Mathematics. Cambridge University Press, Cambridge, I999.

Reviel Netz. Imagination and layered ontology in Greek mathematics. Configurations, I7(I): I9-50, 2009.

Dmitri Nikulin. Imagination and mathematics in Proclus. Ancient Philosophy, 28:153-I72, 2008.

Dominic O'Meara. Pythagoras Revived: Mathematics and Philosophy in Late Antiquity. Oxford University Press, Oxford, I989.

Marco Panza. What is new and what is old in Viète's Analysis Restituta and Algebra Nova, and where do they come from? Some reflections on the relations between algebra and analysis before Viète. Revue d'Histoire des Mathématiques, I3(I):85-I53, 2007.

Blaise Pascal. L'imagination, dans l'édition électronique des Pensées, 20I5. URL http://www. penseesdepascal.fr/Vanite/Vanite31-moderne. php. Edited by Dominique Descotes and Gilles Proust.

Moritz Pasch. Vorlesungen über neuere Geometrie. B.G. Teubner, Leipzig, I 882.

Plato. Republic. Hackett, Indianapolis, 2004. Translated by C.D.C. Reeve.

Jean-Victor Poncelet. Traité des propriétés projectives des figures. Bachelier, Paris, I 822.

Jean Prestet. Nouveaux élémens des mathématiques, volume I. André Pralard, Paris, I689.

Proclus. A Commentary on the First Book of Euclid's Elements. Princeton University Press, Princeton, I992. Translated from Greek by Glenn R. Morrow.

David Rabouin. What Descartes knew of mathematics in I628. Historia Mathematica, 37: 428-459, 20 IO.

David Rabouin. Proclus' conception of geometric space and its actuality. In Vincenzo De Risi, editor, Mathematizing Space: The Objects of Geometry from Antiquity to the Early Modern Age, pages I05-I42. Birkhäuser, Heidelberg, 2015.

Charles-René Reyneau. Analyse demontrée ou La methode de resoudres les problemes des mathematiques, volume I. Jacques Quillau, Paris, I708. 
André Robinet. La philosophie malebranchiste des mathématiques. Revue d'histoire des sciences et de leurs applications, I4 (3-4):205-254, I96I.

Sabine Rommevaux. The transmission of the Elements to the Latin West: three case studies. In The Oxford Handbook of the History of Mathematics, pages 687-706. Oxford University Press, Oxford, 2009.

Chikara Sasaki. Descartes's Mathematical Thought. Springer, Dordrecht, 2003.

Dirk Schlimm. Pasch's philosophy of mathematics. The Review of Symbolic Logic, 3(I):93-I I 8, 20 IO.

Gert Schubring. Conflicts between Generalization, Rigor, and Intuition. Springer, New York, 2005. Dominique Tournès. Diagrams in the theory of differential equations (eighteenth to nineteenth centuries). Synthese, I 86:257-288, 2012.

Theo Verbeek, Erik-Jan Bos, and Jeroen van de Ven, editors. The Correspondence of René Descartes: I643. Department of Philosophy, Utrecht University, 2003. With contributions of Henk Bos, Carla Rita Palmerino and Corinna Vermeulen.

François Viète. The Analytic Art. Kent State University Press, I983. Translated by T. Witmer.

Department of Philosophy, University of Illinois at Urbana-Champaign, ios Gregory Hall, 8io South Wright Street, Urbana, IL 6i8oi, USA, and Institut d’études avancées d’Aix-Marseille (IMéRA), 2 Place LeVerrier, Marseille, France

E-mail address: andrew.arana@gmail .com 